\title{
Electromyographic Evaluation of Early Stage Results of Exoscopic Microdecompressive Spinal Surgery in Dogs
}

\author{
Hakan Salci ${ }^{1}$, Hilal Acar' ${ }^{1}$ \&evlut Ozgur Taskapilioglu ${ }^{2}$
}

\begin{abstract}
Background: Spinal surgical interventions are generally used in the treatment of various spinal pathologies such as vertebral fracture, luxation-subluxation, congenital vertebral deformities, discal hernia, infection and tumor. Minimally invasive spinal surgery contributes to rapid recovery by reducing iatrogenic muscle damage and postoperative pain. In minimally invasive spinal surgery, a new hybrid imaging technique, the exoscope, has been developed in the last decade. The purpose of this study was to report efficacy of the exoscopic microdecompressive spinal surgery (MDSS) and its early postoperative electromyography (EMG) results in dogs.

Materials, Methods \& Results: The material of this study consisted of the owned 10 dogs with spinal cord injury resulted from the different etiologies. On the basis of examinations, medical support (fluid therapy, corticosteroid, etc.) was applied to the required dogs. Exoscopic MDSS was performed under general anesthesia in dogs. The neurologic, radiologic and EMG examination were completed at pre- and postoperative periods. EMG results at postoperative 1st week showed increased conduction velocity and amplitudes in 3 cases. There was no significant change in a case. And, there was a slight slowdown in conduction velocity and significant decrease in amplitudes in a case. At postoperative 4th week, ther was increased conduction velocity and amplitudes in 8 cases and needle EMG showed that spontan muscle activity was normal in 5 cases, mild in 2 cases, moderate a case and severe in a case. But spontan muscle activity was unfollowed in a case. Postoperative outcomes were poor in 3 cases, fair in 3 cases, good in 3 cases and unfollowed in a case.

Discussion: Spinal cord injuries encountered in veterinary medicine have significant morbidity and mortality. In spinal patients, in addition to neurological examination, lesion localization can be determined using imaging techniques such as radiology, computed tomography, and MRI. EMG and somatosensory evoked potentials examinations are used to evaluate quantitative functional recovery, especially in spinal cord injuries. EMG also provides an opportunity to evaluate muscle activation patterns during recovery. Exoscopic spinal surgery is the newest hybrid imaging technique. Exoscopic MDSS facilitated manipulation by providing adequate illumination and vision at the exploration site. Exoscopic MDSS has the advantages of microscopic surgery and is a new technique that can be applied in dogs with spinal pathology.
\end{abstract}

Keywords: dog, electromyography, exoscope, microdecompressive spinal surgery. 


\section{INTRODUCTION}

Spinal surgical interventions are generally used in the treatment of various spinal pathologies such as vertebral fracture, luxation-subluxation, congenital vertebral deformities, discal hernia, infection and tumor [30]. In recent years, minimally invasive surgical techniques have taken part to replace conventional spinal surgery, because wide muscle dissection and retraction required exposing the spinal cord in conventional techniques may result in significant postoperative pain, intraoperative blood loss and impaired muscle function $[13,19,30]$.

Minimally invasive spinal surgery contributes to rapid recovery by reducing iatrogenic muscle damage and postoperative pain [12,19,28,30,34]. However, in minimally invasive spinal surgery, complications such as inadequate decompression and neurological injury may be encountered if adequate and appropriate exploration of the spinal region is not provided $[12,19]$. In minimally invasive spinal surgery, a new hybrid imaging technique, the exoscope, has been developed in the last decade $[10,16,20,26]$. This imaging technique, which is similar to endoscopy, provides the advantage of more magnification, wider focal distance and better surgical manipulation for microneurosurgery, while nonstereoscopic vision and limited manipulation in deep organs are the main disadvantages $[1,10,16-18,20,26]$.

Electromyography (EMG) allows the evaluation of motor units in muscle groups [3]. EMG provides important data for neurosurgeons by providing information on localization of undiagnosed upper motor neuron (UMN) or lower motor neuron (LMN) lesions [27]. In severe spinal cord injury causing motor and sensory loss, EMG is used in addition to neurological reflexes for functional evaluation $[4,12]$. The use of nerve conduction velocity studies and needle EMG is important for determining preclinical re-innervation in partial or total denervated muscles $[2,12]$. The prognosis of spinal damage varies due to trauma and underlying acute or chronic neurological disorder [23]. Surgical treatment of spinal cord pathologies is of great importance for prognosis. Therefore, EMG examination, which is more sensitive than clinical and neurological examinations, is gaining importance to determine neurological and functional return $[3,12,21]$.

In this study, it was aimed to report efficacy of the exoscopic MDSS and its early postoperative EMG results in dogs.

\section{MATERIALS AND METHODS}

The material of this study consisted of the owned ten $\operatorname{dogs}(\mathrm{n}=10)$ with spinal cord injury resulted from the different etiologies that presented to surgery clinics.

\section{Clinic and neurologic examinations}

After obtaining the history from the owners of the dogs, they were immobilized on a flat stretcher considering the suspicion of spinal pathology. Routine clinical (pulsation and respiration rates, body temperature, mucous membrane color, capillary filling time and evaluation of lymph nodes) and neurological examinations (mental status, posture and gait, cranial nerves, postural reactions, spinal reflexes, sensory evaluation, muscle atrophy, etc.) of the dogs were performed. On the basis of examinations, medical support (fluid therapy, corticosteroid, etc.) was applied to the required dogs as recommended previously [6,9].

\section{EMG examinations}

Evaluation of conduction velocities and spontaneous muscle activities (SMA) were performed as described previously at pre- and postoperative $1^{\text {st }}$ and $4^{\text {th }}$ weeks $[32,33]$. EMG examinations of all cases were performed by EMG device (Keypoint $\left.4^{\circledR}\right)^{1}$. Motor conduction velocities (MCV) and SMA of the cases were evaluated. To evaluate the MCV of n. tibialis, compound muscle action potential (CMAP) was recorded by supramaximal stimulation at two points with monopolar needle electrodes throughout the nerve course. CMAP was evaluated for distal latency, amplitude and nerve conduction velocity. In terms of conduction velocity, EMG findings were assessed as normal $(>60 \mathrm{~m} / \mathrm{s})$, decreased $(<60 \mathrm{~m} / \mathrm{s})$ and none. At needle EMG, SMA of $m$. interdigitalis, $m$. tibialis anterior, $\mathrm{m}$. gastrocnemius, $\mathrm{m}$. vastus lateralis, $\mathrm{m}$. quadriceps femoris was examined with the help of concentric needle electrode $(50 \times 0.45 \mathrm{~mm}(2$ " x 26 G). SMA was evaluated as normal, mild denervation (fibrillation potential and positive sharp wave) and severe denervation (continuous fibrillation potential).

\section{Radiologic and Magnetic resonance imaging (MRI) examinations}

Radiographs of the suspected pathological area on the vertebral column were taken in lateral and ventrodorsal positions. MRI was performed in some dogs with the permission of the owners. All pre- and postoperative findings of the dogs were recorded. 
Anesthesia

Peripheral vascular access was opened prior to anesthesia, and infusion of lactated ringer solution $(\mathrm{LRS})^{2}$ and methylprednisolone sodium succinate MPSS (Prednol) ${ }^{3}$ were administered at recommended doses [6] considering to the urgency of the patient. General anesthesia was achieved with a combination of ketamine $\mathrm{HCl}$ (Alfamine) ${ }^{4}$ and diazepam (Diazem) ${ }^{5}$ at the rate of $1 / 1$ for induction. Isoflurane (Forane) ${ }^{6}$ at $2 \%$ concentration with $100 \%$ oxygen after intubation was administered for general anesthesia. Capnography, $\mathrm{SPO}_{2}$ and electrocardiography were performed for monitorization during general anesthesia.

Surgery

All operations were performed by the same working team. According to the surgical technique to be applied after shaving and disinfection of the operation area, the cases were placed and positioned on the operation table. The surgical site was covered with sterile drapes and incisions and dissections were performed according to the surgical technique. An exoscope $\left(\text { VITOM }^{\circledR} 25\right)^{7}$ [Figure 1] was used to enlarge the image of the vertebral area to be operated and for MDSS. Considering to the pvertebral pathology, if need, vertebral stabilization was performed to some cases. After the operative procedures were completed, hemovac micro drain was placed in the surgical area for drainage following to the surgery.

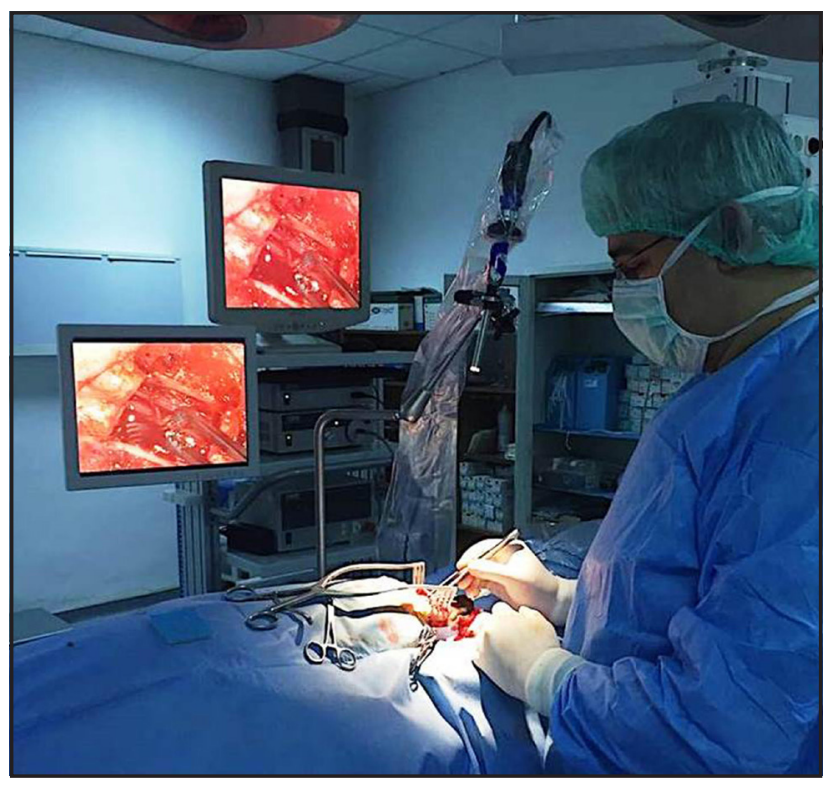

Figure 1. This operation views presents the exoscope during exoscopic microdecompressive spinal surgery (MDSS).
Postoperatively, Prednol ${ }^{3}$ [2 mg/kg, iv, bid], furosemide (Desal) ${ }^{8}$ [2 $\mathrm{mg} / \mathrm{kg}$, iv, qd], LRS2 [10 $\mathrm{mL} / \mathrm{kg}$, infusion, bid], ranitidine (Ranitab) ${ }^{9}[2 \mathrm{mg} /$ $\mathrm{kg}$, sc., bid], carprofen (Rimadyl) ${ }^{10}[4 \mathrm{mg} / \mathrm{kg}$, oral, bid] and cefazolin $\mathrm{Na}(\mathrm{Sefazol})^{3}$ [20 mg/kg, iv, tid] were administered to the cases. Routine medical and physical cares were performed, and cases were kept in soft-bottomed boxes durin postoperative period.

\section{RESULTS}

Table 1 provides information about the signalment of the cases, the etiology of trauma, the presentation time of the case, specific diagnosis based on clinical, radiological and neurological examination, and surgical interventions.

The presentation time of the cases in the clinic ranged from 1 day to 7 months.

\section{Preoperative neurological examination results}

The mental status and cranial nerve examinations were normal in all patients except for case 8 in preoperative period. In cases $1,2,3,5$ and 6, hyporeflexia was evident in the hind limbs. There was a deep pain sensation in cases 1, 2, 3 and 6, whereas there was no deep pain sensation in case 5. Urinary retention and mild anal tone loss were detected in cases 1, 2, 3, 5 and 6. In case 4, hyperreflexia and extensor rigidity were present in all extremities and there was no deep pain sensation. In cases 7 and 9, the reflexes of the front limbs were normal; there was significant hyperreflexia and deep pain sensation in the hind limbs. In case 8 , mental status was depressive, and cranial nerves abnormalities (anisocoria, decreased pupillar reflex) were detected. Extensor rigidity was evident in all extremities of the same patient and hyperreflexia was present in the examination of spinal reflexes and there was no deep pain sensation. In case 10, Schiff Sherrington syndrome was detected and there was no deep pain sensation. Palpation showed mild muscle atrophy in case 1 , moderate in case 2, 5, 6, 7 and severe in case 3 . There was no muscular atrophy in cases 4 , 8,9 and 10. The neurological problems of the cases were paraparesis $(7 / 10)$, tetraparesisis $(3 / 10)$ [Table $2]$ and neurological lesion localizations were cervical (2/10), thoracolumbal (2/10), lumbar (5/10) and lumbosacral (1/10) regions (Table 1). 
Table 1. Signalment, etiology of trauma, presentation time, diagnosis and surgical interventions of the cases.

\begin{tabular}{|c|c|c|c|c|c|}
\hline Case & Signalment & Etiology & $\begin{array}{l}\text { Presentation } \\
\text { time }\end{array}$ & Diagnosis & Surgical intervention \\
\hline 1 & $\begin{array}{l}\text { French Bulldog, } \\
\text { 9-year-old, } \delta\end{array}$ & Idiopathic & 7 days & $\begin{array}{c}\mathrm{L}_{6}-\mathrm{L}_{7} \\
\text { disc herniation }\end{array}$ & $\begin{array}{l}\text { Left hemilaminectomy and } \\
\text { foraminotomy }\end{array}$ \\
\hline 2 & $\begin{array}{l}\text { Yorkshire Terrier, } \\
\text { 4-year-old, }+\end{array}$ & Idiopathic & 10 days & $\begin{array}{c}\mathrm{L}_{6}-\mathrm{L}_{7} \\
\text { disc herniation }\end{array}$ & $\begin{array}{l}\text { Right hemilaminectomy and } \\
\text { discectomy }\end{array}$ \\
\hline 3 & $\begin{array}{l}\text { Mixed-breed, } \\
1 \text {-year-old, } q\end{array}$ & Gunshot injury & 6 months & $\begin{array}{c}\text { Bullet } \\
\text { in } \mathrm{L}_{4} \text { corpus vertebra }\end{array}$ & Right hemilaminectomy \\
\hline 4 & $\begin{array}{l}\text { Cane corso, } \\
\text { 5-month-old, } \widehat{\delta}\end{array}$ & $\begin{array}{l}\text { Motor vehicle } \\
\text { accident }\end{array}$ & 1 day & Atlantoaxial luxation & $\begin{array}{l}\text { Laminotomy and } \\
\text { vertebral stabilization }\end{array}$ \\
\hline 5 & $\begin{array}{l}\text { Mixed-breed, } \\
\text { 1-year-old, } \widehat{\jmath}\end{array}$ & $\begin{array}{l}\text { Motor vehicle } \\
\text { accident }\end{array}$ & 15 days & $\mathrm{L}_{3-} \mathrm{L}_{4}$ luxation & $\begin{array}{c}\text { Dorsal laminectomy and } \\
\text { vertebral stabilization }\end{array}$ \\
\hline 6 & $\begin{array}{l}\text { Yorkshire Terrier, } \\
\text { 5-year-old, }+\end{array}$ & Idiopathic & 7 months & $\begin{array}{c}\mathrm{L}_{7}-\mathrm{S}_{1} \\
\text { disc herniation }\end{array}$ & $\begin{array}{l}\text { Left hemilaminectomy and } \\
\text { discectomy }\end{array}$ \\
\hline 7 & $\begin{array}{l}\text { Mixed-breed, } \\
\text { 2-year-old, },+\end{array}$ & Idiopathic & 5 days & $\begin{array}{c}\mathrm{T}_{13}-\mathrm{L}_{1} \\
\text { disc herniation }\end{array}$ & $\begin{array}{l}\text { Left hemilaminektomi and } \\
\text { vertebral stabilization }\end{array}$ \\
\hline 8 & $\begin{array}{l}\text { Miniature Pinscher, } \\
\text { 4-year-old, } q\end{array}$ & $\begin{array}{l}\text { Motor vehicle } \\
\text { accident }\end{array}$ & 2 days & Atlantoaxial luxation & $\begin{array}{c}\text { Laminotomy and } \\
\text { vertebral stabilization }\end{array}$ \\
\hline 9 & $\begin{array}{l}\text { Dogo Argentino, } \\
\text { 3.5-month-old, },+\end{array}$ & $\begin{array}{l}\text { Motor vehicle } \\
\text { accident }\end{array}$ & 2 days & $\begin{array}{c}\text { Fracture of } \mathrm{L}_{3} \text { corpus } \\
\text { vertebra }\end{array}$ & $\begin{array}{c}\text { Dorsal laminectomy and } \\
\text { vertebral stabilization }\end{array}$ \\
\hline 10 & $\begin{array}{l}\text { Golden Retriever, } \\
\text { 6-month-old, } ठ \widehat{\sigma}\end{array}$ & $\begin{array}{l}\text { Motor vehicle } \\
\text { accident }\end{array}$ & 1 day & $\begin{array}{c}\mathrm{T}_{13}-\mathrm{L}_{1} \\
\text { Dorsal dislocation }\end{array}$ & Dorsal laminectomy \\
\hline
\end{tabular}

\section{Preoperative EMG results}

In cases 4 and 10, there was no pathological finding in the hind limb muscles in needle EMG. The degree of positive sharp waves with fibrillation potentials indicating denervation of SMA was mild (3/10) in cases 1,8 , and 9, moderate (3/10) in cases $2,5,6$ and 7 , and severe $(1 / 10)$ in case 3 . The conduction rate of n.tibialis was recorded in the lowest case 1 (17.4 $\mathrm{m} / \mathrm{s})$ and the highest case in $4(92.6 \mathrm{~m} / \mathrm{s})$. Conduction velocity was recorded below $60 \mathrm{~m} / \mathrm{s}$ in cases 1 and 7 , but above $60 \mathrm{~m} / \mathrm{s}$ in the other cases (9/10). The lowest conduction velocity was recorded in case 1 with the diagnosis of disceal hernia. Amplitudes were also significantly lower in the same case (the lowest amplitude was $0.3 \mathrm{mV}$ and the highest was $24.0 \mathrm{mV}$ ). In cases 1, 2 and 3, the amplitude was below $5 \mathrm{mV}$ (Table 3).

\section{Radiological findings}

Radiologically, case 1 and 7 had no pathological findings on the radiograms. In case 2 , mineralization was detected in the $\mathrm{L}_{6-7}$ intervertebral space. The bullet was observed in the $\mathrm{L}_{4}$ corpus vertebra of case 3 . In cases 4 and 8 , there was no coapitation between the articular faces of the atlas and the axis and the axis shifted laterally. In case 5, fracture between the $\mathrm{L}_{3-4}$ and ventral dislocation of $\mathrm{L}_{4}$ were observed (Figure 2). In case 6, there was mineralization in the intervertebral region between $\mathrm{L}_{7}-\mathrm{S}_{1}$. Case 9 had compression fracture of $\mathrm{L}_{3}$ corpus vertebra. In case 10 , dorsal dislocation between $\mathrm{T}_{13}-\mathrm{L}_{1}$ was detected.

\section{MRI findings}

MRI examinations were only performed in case 1, 2 and 7 preoperatively. T2 sequence sagittal and transverse cross-sectional examination revealed hyperintense disc compression and compression in the spinal cord between $\mathrm{L}_{6-7}$ in cases 1 (Figure 3) and 2 and T13-L1 in case 7.

\section{Surgical findings}

In all cases, exoscopic MDSS technique was performed in cervical 2/10, thoracolumbal 2/10, lumbar $5 / 10$ and lumbosacral 1/10 regions according to lesion localization. The vertebral stabilization techniques applied in the related anatomic regions are given in Table 1. No surgical wound complication was observed in all cases. 


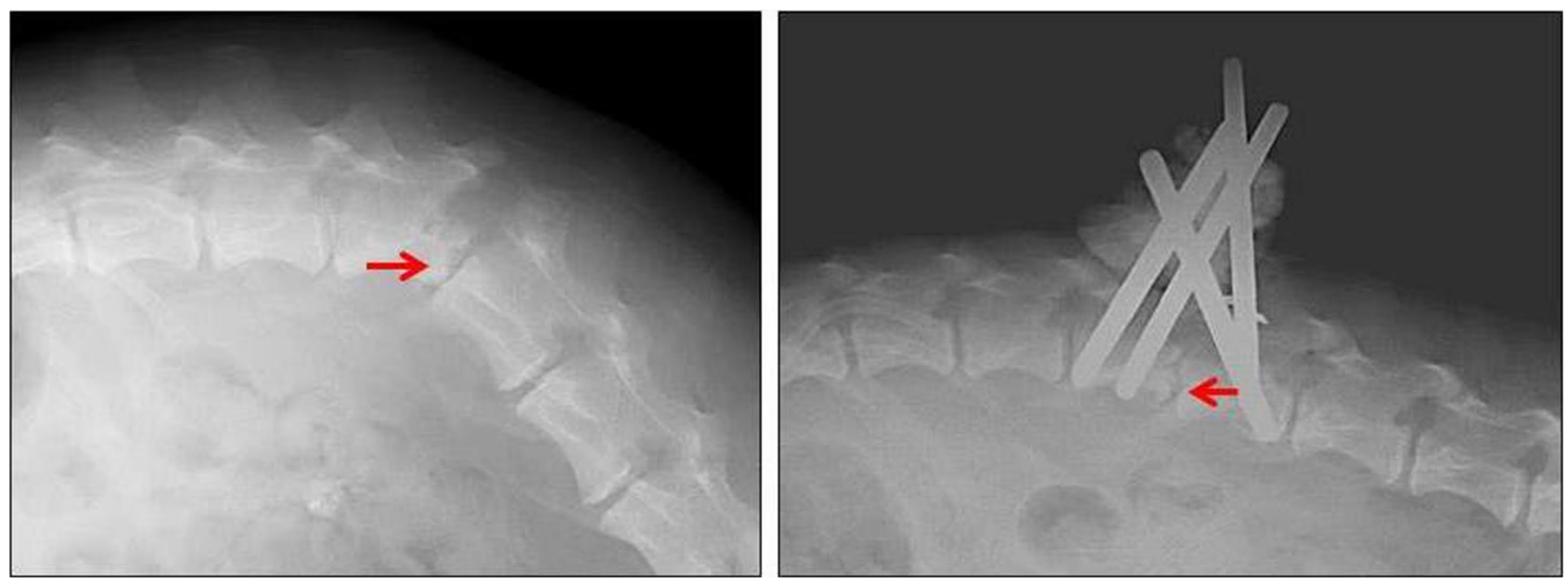

Figure 2. The pre- and postoperative lateral radiographies of case 5. Right arrow: shows the pathology between (subluxation and ventral dislocation of L4), and left arrow: points out the stabilized L3-4 vertebras and reduction of the intervertebral space following surgery.
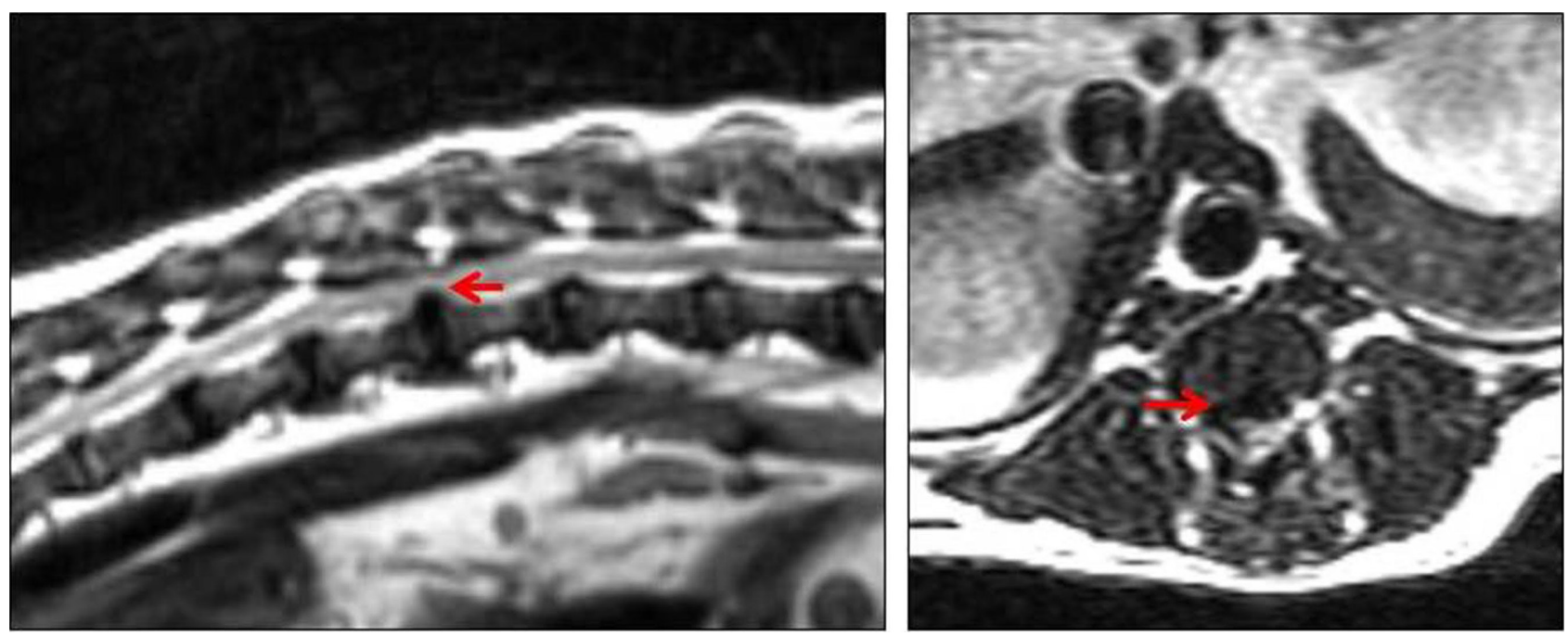

Figure 3. T2 sequence sagittal and axial cross-sectional MRI views of case 7. Left arrow: shows sagittal plane hyper intense disc compression to the spinal cord between T13-L1. Right arrow: points out the axial plan disc herniation to spinal cord.

\section{Postoperative neurological results}

In the $1^{\text {st }}$ postoperative week, case 1 was able to stand but could not move on its own when supported, and spinal reflexes was normal and there was deep pain sensation. At postoperative 4th week, this case was able to stand but could not move alone when supported. In cases 2,6 and 7 , at postoperative $4^{\text {th }}$ week, proprioception, voluntary movement and spinal reflexes were present, and they also had voluntary urination and defecation. In case 3 , at postoperative $4^{\text {th }}$ week, she was able to stand when supported, but she could not move voluntarily, and spinal reflexes were present. Case 4 and 8 with atlantoaxial stabilization had deep pain sensation at postoperative 1st weeks. These dog were also able to stand and wolk on their own. At postoperative $4^{\text {th }}$ week, case 5 was able to load the hind limbs when supported, but could not move on its own. In case 10, after the dorsal laminectomy, it was seen that the spinal cord was severely lasered and 2/3 of the spinal cord ruptured. There was no functional return and deep pain sensation in the $1^{\text {st }}$ postoperative week but spinal reflexes were present (Table 2).

\section{Postoperative EMG results}

Postoperative 1st week EMG evaluation showed an increase in conduction velocity and an increase in amplitudes in cases 2, 3 and 6. There was no significant change in case 3 . In case 10 , there was a slight slowdown in conduction velocity and significant decrease in amplitudes. Since cases 1, 5, 7 and 9 did not come to the control, these cases could not be evaluated. Needle EMG findings showed a moderate decrease in denervation potential of cases 2 and 6 . In case 3 , severe denervation potentials were replaced by 
moderate denervation potentials. In case 4, needle EMG findings were normal. In case 8 , the denervation potentials completely disappeared in the first postoperative week, and EMG examination at the postoperative 4th week showed an increase in conduction velocity and amplitudes. The rate of conduction was lowest in case $1(50.0 \mathrm{~m} / \mathrm{s})$ and highest in case $6(94.1 \mathrm{~m} / \mathrm{s})$. In needle EMG, denervation potentials were mild in cases 5 and 6 , and moderate in case 3 . There was no SMA in cases 1, 2, 4, 7 and 8. Postoperative followup of case 9 could not be performed because the patient owner did not bring this case. Detailed EMG results of all cases are given in Table 3.

Table 2. Tabulation of preoperative, postoperative $1^{\text {st }}$ and $4^{\text {th }}$ weeks neurological examination and surgical outcomes.

\begin{tabular}{|c|c|c|c|c|c|c|c|c|c|c|}
\hline \multirow[b]{2}{*}{ Case } & \multicolumn{3}{|c|}{ Preoperative } & \multicolumn{3}{|c|}{ Postoperative $1^{\text {st }}$ week } & \multicolumn{3}{|c|}{ Postoperative $4^{\text {th }}$ week } & \multirow[b]{2}{*}{ Outcome } \\
\hline & $\begin{array}{l}\text { Volunteer } \\
\text { movement }\end{array}$ & $\begin{array}{l}\text { Spinal } \\
\text { reflexes }\end{array}$ & $\begin{array}{l}\text { Deep } \\
\text { pain }\end{array}$ & $\begin{array}{l}\text { Volunteer } \\
\text { movement }\end{array}$ & $\begin{array}{l}\text { Spinal } \\
\text { reflexes }\end{array}$ & $\begin{array}{l}\text { Deep } \\
\text { pain }\end{array}$ & $\begin{array}{l}\text { Volunteer } \\
\text { movement }\end{array}$ & $\begin{array}{l}\text { Spinal } \\
\text { reflexes }\end{array}$ & $\begin{array}{l}\text { Deep } \\
\text { pain }\end{array}$ & \\
\hline 1 & Paraparesis & $\begin{array}{c}\text { Front limbs normal } \\
\text { Hind limbs hyporeflexia }\end{array}$ & + & ++ & + & + & ++ & + & + & Poor \\
\hline 2 & Paraparesis & $\begin{array}{c}\text { Front limbs normal } \\
\text { Hind limbs hyporeflexia }\end{array}$ & + & ++ & + & + & +++ & + & + & Fair \\
\hline 3 & Paraparesis & $\begin{array}{c}\text { Front limbs normal } \\
\text { Hind limbs hyporeflexia }\end{array}$ & + & ++ & + & + & ++ & + & + & Poor \\
\hline 4 & Tetraparesis & $\begin{array}{l}\text { Extensor rigidity all } \\
\text { limbs hyperreflexia }\end{array}$ & - & +++ & + & + & +++ & + & + & Good \\
\hline 5 & Paraparesis & $\begin{array}{c}\text { Front limbs normal } \\
\text { Hind limbs hyporeflexia }\end{array}$ & - & - & + & + & ++ & + & + & Fair \\
\hline 6 & Paraparesis & $\begin{array}{c}\text { Front limbs normal } \\
\text { Hind limbs hyporeflexia }\end{array}$ & + & - & + & + & ++ & + & + & Fair \\
\hline 7 & Paraparesis & $\begin{array}{c}\text { Front limbs normal } \\
\text { Hind limbs hyporeflexia }\end{array}$ & + & ++ & + & + & +++ & + & + & Good \\
\hline 8 & Tetraparesis & $\begin{array}{l}\text { Extensor rigidity all } \\
\text { limbs hyperreflexia }\end{array}$ & - & ++ & + & $\begin{array}{c}2^{\text {nd }} \\
\text { week }\end{array}$ & +++ & + & + & Good \\
\hline 9 & Paraparesis & $\begin{array}{c}\text { Front limbs normal } \\
\text { Hind limbs hyporeflexia }\end{array}$ & - & & & & Unfollowed & & & \\
\hline 10 & Paraparesis & Schiff Sherrington & - & - & + & - & - & + & - & Poor \\
\hline
\end{tabular}

-: absent; +: intact; ++: volunteer movement when supported; +++: movement by itself; Poor: ability to walk absent; Fair: weakness at hind limbs; Good: complete recovered.

Table 3. EMG results of the cases at preoperative and postoperative $1^{\text {st }}$ and $4^{\text {th }}$ weeks.

\begin{tabular}{|c|c|c|c|c|c|c|c|c|c|}
\hline \multirow{3}{*}{ Case } & \multicolumn{3}{|c|}{ Preoperative EMG } & \multicolumn{3}{|c|}{$1^{\text {st }}$ week EMG } & \multicolumn{3}{|c|}{$4^{\text {th }}$ week EMG } \\
\hline & \multicolumn{2}{|c|}{$\mathrm{NCV}(\mathrm{m} / \mathrm{s})$} & \multirow{2}{*}{ Needle EMG } & \multicolumn{2}{|c|}{$\mathrm{NCV}(\mathrm{m} / \mathrm{s})$} & \multirow{2}{*}{ Needle EMG } & \multicolumn{2}{|c|}{$\mathrm{NCV}(\mathrm{m} / \mathrm{s})$} & \multirow{2}{*}{ Needle EMG } \\
\hline & $\mathrm{R}$ & $\mathrm{L}$ & & $\mathrm{R}$ & $\mathrm{L}$ & & $\mathrm{R}$ & $\mathrm{L}$ & \\
\hline 1 & 17.4 & 19.2 & Mild & & & & 50 & 67.6 & Normal \\
\hline 2 & 62.5 & 87.7 & Moderate & 82 & 95.2 & Mild & 70.9 & 91.7 & Normal \\
\hline 3 & 73.2 & 74.2 & Severe & 75.9 & 80.3 & moderate & 57.9 & 80.3 & Moderate \\
\hline 4 & 75.6 & 92.6 & Normal & 82.4 & 80.5 & Normal & 82.4 & 80.5 & Normal \\
\hline 5 & 89.2 & 82.2 & Moderate & & & & 91.5 & 78.7 & Mild \\
\hline 6 & 80 & 81.6 & Moderate & 87.9 & 94,1 & Mild & 87 & 104 & Mild \\
\hline 7 & 59.6 & 65.7 & Moderate & & & & 74.5 & 70.3 & Normal \\
\hline 8 & 50.7 & 64.8 & Mild & 56.7 & 62 & Normal & 65.8 & 65.6 & Normal \\
\hline 9 & 78.7 & 63.9 & Mild & & Unfoll & & & Unfol & \\
\hline 10 & 76.0 & 65.0 & Normal & 60.7 & 63 & Moderate & 45 & 45.7 & Severe \\
\hline
\end{tabular}

NCV: conduction velocity; R: right hind limb; L: left hind limb; Normal: no spontaneous muscle activity; Mild: rare fibrillation potential and positive sharp wave; Moderate: prominent fibrillation potential and positive sharp wave; Severe: continuous fibrillation potential. 


\section{DISCUSSION}

Spinal cord injuries encountered in veterinary medicine have significant morbidity and mortality [5,7,22,23]. Pulmonary contusion, pneumothorax, rib fractures, extremity fractures, pelvic fractures, abdominal organ injuries and head trauma are usually seen with spinal trauma [7,8]. Among the most common causes of spinal trauma in dogs are motor vehicle accidents, falling from heights, animal fightings, gunshot and iatrogenic injuries $[5,7,9]$. In the presented study, the etiology of the cases with spinal pathology was determined as gunshot injury (1/10), idiopathic causes (4/10) and motor vehicle accidents (5/10).

The main objective in neurological examination is to determine the localization of neural lesions. In neurological examination, the presence of nystagmus showing central dysfunction of cranial nerves II, III, V and VII, anisocoria, decreased or absent of palpebral and/ or pupillary reflex indicate head trauma [9,31]. Due to the severity of trauma, irreversible damage to the thoracolumbar spinal region causes complete loss of sensation in the hind limbs [14]. In this study, the presence of paraparesis and the laceration of the spinal cord during the operation in case 10 were compatible with severe myelomalesis. Compared with preoperative period, in postoperative 4th week EMG findings, the gradual slowdown in conduction velocity, decrease in amplitudes and significant increase in SMA were evidence of irreversible pathology. In general, acute disc herniation is observed between $\mathrm{T}_{11}-\mathrm{L}_{1}$ and chronic disc hernia occurs between caudal cervical and $\mathrm{L}_{7}-\mathrm{S}_{1}$ vertebrae $[14,24]$. In our study, acute and chronic discal hernias were observed in case 7 and in cases 1,2 and 6 , respectively.

In spinal patients, in addition to neurological examination [7,8,27,31], lesion localization can be determined using imaging techniques such as radiology, computed tomography, and MRI [7-9,24,27]. MRI provides important anatomical detail in the diagnosis of disceal hernia, but its incorrect results reduce its reliability [14,27]. In addition, in a study investigating the correlation between MRI findings and the severity of spinal cord injury, no statistical correlation was reported between spinal cord bleeding, contusion and edema and severity of spinal cord injury [24]. In contrast to MRI, EMG confirms that the lesions are physiologically important and prevents unnecessary interventions [27]. Moreover, MRI technique does not show the clinical findings of neurological pathology completely in pre- and postoperative period and it is reported to be insufficient to determine the prognosis $[24,35]$. And, EMG and somatosensory evoked potentials examinations are used to evaluate quantitative functional recovery, especially in spinal cord injuries. Changes in the peripheral nerve in chronic spinal cord injuries are evaluated by motor nerve conduction studies [12]. At the same time, EMG provides an opportunity to evaluate muscle activation patterns during recovery $[4,12]$. In this study, radiological and MRI examinations of the spine were performed to determinate the localization of the spinal pathology of the dogs and EMG examinations were also made to evaluate the neurological problem.

Minimally invasive surgery is widely applied in neurosurgery in human medicine, especially in lumbar spinal cord decompression [28]. However, it has been reported that it also provides good results in cervical vertebra surgery, and even in a study, it provides minimal blood loss and shortens the length of hospital stay [19]. In a study comparing minimally invasive surgery and open lumbar decompression, it is reported to be as reliable as conventional technique, and recovery is faster and the patient gains function in a short postoperative time [28]. Despite all these advantages, since it is still developing in veterinary surgery, it has been reported that it will be beneficial to continue with conventional techniques [12]. Here, as alternative to conventional technique, MDSS was planned to minimalize the surgical damage in the dogs. Exoscopic spinal surgery is the newest hybrid imaging technique $[10,16,20,26]$. Since MDSS has important disadvantages such as inadequate exploration and decompression, these disadvantages can be overcome by using the exoscopic imaging technique $[1,10]$. Exoscopic brain and spinal surgery has been reported to be an innovative development with the advantages of surgical microscopy [1]. In a study, it has been reported that spinal surgery provides ease of vision in all directions thanks to the perpendicularly placed exoscope and compact robotic arm [10]. In another study in which spinal surgical procedures are performed, it is reported that the exoscope is very advantageous with its wide exploration in tumor resections and with its ability to provide images in deep tissues and independent movement [18]. In the presented study, exoscopic spinal surgery was performed in dorsal hemilaminectomy and discectomy operations of thoracolumbal, lumbar, lumbosacral regions without any complication. Exoscopic 
MDSS facilitated manipulation by providing adequate illumination and vision at the exploration site. Particularly in case 4 , significant positive results were observed such as postoperative functional gain in a short postoperative time, return of motor conduction rate to reference values, significant increase in amplitude and absence of SMA.

Performing surgical decompression within the first 6 hours following spinal cord injury contributes positively to postoperative recovery $[5,15,25]$. However, the lack of normal vital signs in trauma patients is a problem for early surgical intervention [29]. Although posttraumatic surgical procedure was postponed in case 5, neurological and EMG findings were positive. In case 3 presented 7 months after the occurrence of spinal pathology, severe spontaneous muscle activity due to denervation observed in preoperative EMG examination decreased postoperative 4th week and increased amplitudes showed that late exoscopic MDSS contributed to recovery even in the late period. The experience of the operator is very important when choosing surgical technique. Ventral approach technique is recommended for atlantoaxial luxations because of its high success rate [29]. In two cases (cases 4 and 8), laminotomy and stabilization procedures were performed with a dorsal approach and full recovery was observed in the postoperative period. In postoperative 4th week EMG findings, although there was no change in conduction velocity, normal amplitudes and distal latency values were a good reflection of functional improvement.

Pre- and postoperative bladder dysfunction is a secondary clinical finding commonly observed due to the severity and localization of spinal cord injury [22,23]. In case 10 , fecal and urinary incontinence developed in the 1 st postoperative week but the urinary bladder was evacuated mechanically. In addition, deep pain sensation in pre- and postoperative neurological examination is an important indicator in determining the severity and prognosis of spinal cord injuries [11,12,14,22,31]. Generally, deep pain sensation provides important information in patients with thoracic, thoracolumbal or lumbar spinal cord lesions [12]. It has been reported that the results of spinal surgery vary in dogs with deep pain sensation loss $[11,14]$, because the assessment of deep pain sensation alone is insufficient to determine spinal cord injury and prognosis [12]. In spite of the subjective data of neurological examination, electrophysiological examinations are diagnostic tools applicable to the evaluation of motor nerve dysfunction [21]. EMG helps to distinguish spinal cord and nerve root lesions due to different distribution of myotomes and peripheral nerves from peripheral nerve injuries by determining denervation even in muscles normally detected in clinical examination $[2,12,27]$. In this presented study, although no atrophy was observed clinically in cases 8 and 9, mild spontaneous muscle activity was detected in needle EMG examination. In addition, in the study, CMAP amplitude reflecting the number of EMG-inducible axons was found to be low in cases 1, 3 and 5 postoperatively, and normal in cases 2, 4, 6, 7 and 8. In the postoperative period, the distal latency value showing muscle dysfunction was prolonged in cases 1 and 3, and was normal in cases 2, 4, 5, 6, 7 and 8. SMA was not recorded in the needle EMG of the dogs brought in 1-2 days after the trauma, but fibrillation potentials indicating denervation of the hind limb muscles were recorded in 9 cases presented to 5 days later following spinal problem. In chronic cases, conduction velocity and amplitudes decreased.

\section{CONCLUSIONS}

In this study, based on EMG examination, which provides important data for the evaluation of postoperative clinical functional return of spinal diseases, exoscopic MDSS has the advantages of microscopic surgery and is a new technique that can be applied in dogs with spinal pathology.

\section{MANUFACTURERS}

${ }^{1}$ Medtronic Danmark A/S. Copenhagen, Denmark.

${ }^{2}$ Eczacibasi Baxter A/S. Istanbul, Turkey.

${ }^{3}$ Mustafa Nevzat A/S. Istanbul, Turkey.

${ }^{4}$ EgeVet Hayvancilik. Izmir, Turkey.

${ }^{5}$ Deva Holding A/S. Istanbul, Turkey.

${ }^{6}$ Abbott Laboratuarlari, Istanbul, Turkey.

${ }^{7}$ Karl Storz Endoscopy-America Inc. El Segundo, CA, USA.

${ }^{8}$ Biofarma A/S. Istanbul, Turkey.

${ }^{9}$ Deva Holding A/S. Istanbul, Turkey.

${ }^{10}$ Pfizer A/S. Istanbul, Turkey.

Acknowledgments. The authors are grateful to the Bursa Uludag University for supporting their work as a scientific research project (Project BUAP (V) - 2015/3).

Ethical approval. Animal procedures were approved by Animal Local Ethics Committee of Bursa Uludag University (Decision 2013 - 17/05).

Declaration of interest. The authors report no conflicts of interest. The authors alone are responsible for the content and writing of this paper. 


\section{REFERENCES}

1 Beez T., Munox-Bendix C., Beseoglu K., Steiger H.J. \& Ahmadi S.A. 2018. First clinical applications of a highdefinition three-dimensional exoscope in pediatric neurosurgery. Cureus. 10(1): e21018.

2 Bergknut N., Smolders L.A., Grinwis G.C., Hagman R., Lagerstedt A.S., Hazewinkel H.A., Tryfonidou M.A. \& Meij B.P. 2013. Intervertebral disc degeneration in the dog. Part 1: Anatomy and physiology of the intervertebral disc and characteristics of intervertebral disc degeneration. The Veterinary Journal. 195(3): 282-291.

3 Calancie B., Molano M.R. \& Broton J.G. 2004. EMG for assessing the recovery of voluntary movement after acute spinal cord injury in man. Clinical Neurophysiology. 115(8): 1748-1759.

4 Calancie B., Molano M.R. \& Broton J.G. 2004. Tendon reflexes for predicting movement recovery after acute spinal cord injury in humans. Clinical Neurophysiology. 115(10): 2350-2363.

5 Can P. \& Beşaltı Ö. 2016. Omurilik hasarında güncel tedavi yöntemleri. Türkiye Klinikleri Veteriner Bilimleri - Cerrahi - Özel Konular. 2(3): 45-49.

6 Dewey C.W. 2013. Neurosurgery. In: Fossum T.W. (Ed). Small Animal Surgery. Philadelphia: Elsevier Mosby, pp.14111565.

7 DiFazio J. \& Fletcher D.J. 2013. Updates in the management of the small animal patient with neurologic trauma. Veterinary Clinics of North America: Small Animal Practice. 43(4): 915-940.

8 Eminaga S., Palus V. \& Cherubini G.B. 2011. Acute spinal cord injury in the cat, causes, treatment and prognosis. Journal of Feline Medicine and Surgery. 13(11): 850-862.

9 Garosi L. 2012. Examining the neurological emergency. In: Platt S. \& Garosi L. (Eds). Small Animal Neurological Emergencies. London: Manson Publishing, pp.15-35.

10 Haider G., Akhtar S., Waqas M., Nizamani W., Jasmine A. \& Enam S.A. 2018. Use of neuro-robotic exoscope for neurosurgery in Pakistan: A cases. Journal of Neurology and Neuroscience. 9(1): 241. doi: 10.21767/2171-6625.1000241

11 Henke D., Vandevelde M., Doherr M.G., Stöckli M. \& Forterre F. 2013. Correlations between severity of clinical signs and histopathological changes in 60 dogs with spinal cord injury associated with acute thoracolumbar intervertebral disc disease. The Veterinary Journal. 198(1): 70-75.

12 Higginbithom M.J., Lanz O.I. \& Carozzo C. 2015. Minimal Invasive Techniques for Spinal Cord and Nerve Root Decompression. In: Fingeroth J.M. \& Thomas W.B. (Eds). Advences in Intervertebral Disc Disease in Dogs and Cats. Philadelphia: Wiley Blackwell, pp.289-293.

13 Holly L.T., Moftakhar P., Khoo L.T., Wang J.C. \& Shamie N. 2007. Minimally invasive 2-level posterior cervical foraminotomy preliminary clinical results. Journal of Spinal Disorders \& Techniques. 20(1): 20-24.

14 Jeffery N.D., Levine J.M., Olby N.J. \& Stein V.M. 2013. Intervertebral disc dejeneration in dogs: consequences, diagnosis, treatment, and future directions. Journal of Veterinary Internal Medicine. 27(6): 1318-1333.

15 Kirby R. 2010. Emergency management of spinal cord lesions. Clinician's Brief. $27-32$.

16 Mamelak A.N., Danielpour M., Black K.L., Hagike M. \& Berci G. 2008. A high-definition exoscope system for neurosurgery and other microsurgical disciplines: preliminary report. Surgical Innovation. 15(1): 38-46.

17 Mamelak A.N., Drazin D., Shirzadi A., Black K.L. \& Berci G. 2012. Infratentorial supracerebellar resection of a pineal tumor using a high definition video exoscope (VITOM). Journal of Clinical Neuroscience. 19: 306-309.

18 Mamelak A.N., Nobuto T. \& Berci G. 2010. Initial clinical experience with a high-definition exoscope system for microneurosurgery. Neurosurgery. 67(2): 476-483.

19 Mikhael M.M., Celestre P.C., Wolf C.F., Mroz T.E. \& Wang J.C. 2012. Minimally invasive cervical spine foraminotomy and lateral mass screw placement. Spine. 37(5): 318-322.

20 Nishiyama K. 2017. From exoscope into the next generation. Journal of Korean Neurosurgical Society. 60(3): 289-293.

21 Okuno S., Kobayashi T. \& Orito K. 2005. Usefulness of combined electrophysiological examinations for detection of neural dysfunction in cats with lumbar hematomyelia. The Journal of Veterinary Medical Science. 67(12): 1265-1268.

22 Olby N., Levine J., Harris T., Munana K., Skeen T. \& Sharp N. 2003. Long-term functional outcome of dogs with severe injuries of the thoracolumbar spinal cord: 87 cases (1996-2001). Journal of the American Veterinary Medical Association. 222(6): 762-769.

23 Park E.H., White G.A. \& Tieber L.M. 2012. Mechanisms of injury and emergency care of acute spinal cord injury in dogs and cats. Journal of Veterinary Emergency and Critical Care. 22(2): 160-178. 
24 Penning V., Platt S.R., Dennis R., Cappello R. \& Adams V. 2006. Association of spinal cord compression seen on magnetic resonance imaging with clinical outcome in 67 dogs with thoracolumbar intervertebral disc extrusion. Journal of Small Animal Practice. 47(11): 644-650.

25 Rabinowitz R.S., Eck J.C., Harper Jr. C.M., Larson D.R., Jimenes M.A., Parisi J.E., Friedman J.A., Yaszemski M.J. \& Currier B.L. 2008. Urgent surgical decompression compared to methylprednisolone for the treatment of acute spinal cord injury. Spine. 33(21): 2260-2268.

26 Ricciardi L., Chaichana K.L., Cardia A., Stifano V., Rossini Z., Olivi A. \& Sturiale C.L. 2019. The exoscope in neurosurgery: an innovative "point of view". A systematic review of the technical, surgical, and educational aspects. World Neurosurgery. 124: 136-144.

27 Sharp N.J.H. \& Wheeler S.J. 2005. Small Animal Spinal Disorders. 2nd edn. London: Elsevier Mosby, pp.57-61.

28 Shih P., Wong A.P., Smith T.R., Lee A.L. \& Fessler R.G. 2011. Complications of open compared to minimally invasive lumbar spine decompression. Journal of Clinical Neuroscience. 18(10): 1360-1364.

29 Shores A. \& Brisson B.A. 2017. Current Tecniques in Canine and Feline Neurosurgery. Philadelphia: Wiley Blackwell, pp.141-235.

30 Skovrlj B., Gilligan J., Cutler H.S. \& Qureshi S.A. 2015. Minimally invasive procedures on the lumbar spine. World Journal of Clinical Cases. 3(1): 1-9.

31 Thomson C. \& Hahn C. 2012. Veterinary Neuroanatomy: A Clinical Approach. Saint Louis: Saunders Elsevier, pp.124-136.

32 van Nes J.J. 1986. An introduction to clinical neuromuscular electrophysiology. Veterinary Quarterly. 8(3): 233-239.

33 van Nes J.J. 1986. Clinical application of neuromuskuler electrophysiology in the dog: a review. Veterinary Quarterly. 8(3): 240-250.

34 Yang S.M., Park H.K., Chang J.C., Kim R.S., Park S.Q. \& Cho S.J. 2013. Minimum 3-year outcomes in patients with lumbar spinal stenosis after bilateral microdecompression by unilateral or bilateral laminotomy. Journal of Korean Neurosurgical Society. 54(3): 194-200.

35 Yaygıngül R. \& Belge A. 2016. Köpeklerde intervertebral disk hastalığı. Türkiye Klinikleri Veteriner Bilimleri - Cerrahi - Özel Konular. 2(3): 60-67. 